\title{
Wieloznaczność poznawcza jako strategia komunikacyjna ${ }^{1}$
}

Język jest pierwotnym medium życia społecznego. Jest narzędziem wykorzystywanym do nadawania publicznego kształtu celom, motywom oraz intencjom ludzi. Jest niezbędny do tego, aby ustanowić i utrzymać poczucie własnego „ja”, aby móc wymieniać się ideami, uczuciami i myślami oraz do ustanowienia wspólnego rozumienia otaczającego świata. Z drugiej strony, znalezienie właściwych słów, gdy ma się do przekazania coś trudnego, jest złożonym i wymagającym zadaniem poznawczym ${ }^{2}$. Przede wszystkim z tego właśnie względu, zdaniem Paul Watzlawick i Jane Beavin, raczej wyjątkiemniż regułą jest, iż komunikacja międzyludzka jest jednoznaczna i precyzyjna. To przekonanie szczególnie często towarzyszy komunikacji w polityce ${ }^{3}$, w której wieloznaczność stosowana jest powszechnie jako strategia służąca zwiększeniu liczby odbiorców, do których apeluje komunikat ${ }^{4}$.

Z kolei zarówno nadawca, jak i odbiorca wnoszą w akt komunikacji odmienne aparaty pojęciowe czy treści pamięciowe, które następnieprocesują w jedyny właściwy sobie sposób. Z tego punktu widzenia wieloznaczność poznawcza, stanowiąc immanentną cechę ludzkiego myślenia, wpisana byłaby na stałe w komunikację . Uobecniana poprzez język stanowi o współistnieniu jednostek w wymiarze

* Mgr, e-mail: karolina.dobrosz@uni.lodz.pl; Uniwersytet Łódzki, Wydział Filologiczny, Katedra Dziennikarstwa i Komunikacji Społecznej.

${ }^{1}$ Artykuł powstał w ramach projektu badawczego finansowanego $\mathrm{z}$ dotacji dla młodych naukowców w roku 2016.

${ }^{2}$ Za: W. Cwalina, Wieloznaczność poznawcza w komunikacji, [w:] Psychologia poznawcza w praktyce: ekonomia, biznes, polityka, red. A. Falkowski, T. Zaleśkiewicz, Wydawnictwo Naukowe PWN, Warszawa 2012, s. 169.

${ }^{3}$ Szeroko i poglądowo o wieloznaczności w komunikowaniu polityków traktuje praca W. Cwaliny, dz. cyt., s. $187-261$.

${ }^{4}$ Por. C. Camden, M.T. Moltey, A. Wilson, White lies in interpersonal communication: A taxonomy and preliminary investigation of social motivations, "Western Journal of Speech Communication” 1984, nr 48(4), s. 309-325; P. Bull, Slippery politicians?, „The Psychologist” 2003, nr 16 (11), s. 592-595; W. Cwalina, tamże.

${ }^{5}$ A. Falkowski, Podobieństwo poznawcze w kategoryzacji percepcyjnej. Badania empiryczne w egzemplarzowym modelu kategoryzacji, „Przegląd Psychologiczny” 1990, nr 33, s. 293-312; 
społecznym. Częściowo odmienny i częściowo zgodny cognitionbackground ${ }^{6}$ komunikujących się podmiotów umożliwia ich wzajemne zrozumienie mimo wieloznaczności jednej strony, warunkując jednocześnie komunikacyjne nieporozumienia - z drugiej ${ }^{7}$. Za ostatnie - z kognitywnego punktu widzenia - odpowiadałyby różne poziomy konceptualizowania komunikowanych treści (w wymiarze jednostkowym): im wyższy poziom konceptualizacji wieloznacznego komunikatu, tym większa rola kreacyjności w procesie nadawczo-odbiorczym ${ }^{8}$. Czy powyższe stanowić może ograniczenie dla efektu perswazyjnego komunikatów operujących wieloznacznością (powszechnie wykorzystywanego w polityce) ${ }^{9}$ ? Artykuł stanowi próbę znalezienia odpowiedzi na tak postawione pytanie ${ }^{10}$.

F. Ferreira, K.G.D. Bailey, V. Ferraro, Good-enough representation in language comprehension, "Current Directions in Psychological Science" 2002, nr 11 (1), s. 11-15.

${ }^{6}$ Przyjęcie optyki kognitywnej w badaniu wieloznaczności pozwala dostrzec i opisać wieloznaczność jako naturalny i nieunikniony komponent każdej komunikacji dokonującej się poprzez język, zależny od kreacyjności, pamięci i wyobraźni komunikujących się podmiotów. Powstawanie znaczeń opiera się, jak twierdził Gilles Fauconnier w Mental Spaces. Aspects of Meaning Construction in Natural Language (Cambridge University Press, Cambride, 1994), na tzw. backstagecognition, tzn. w oparciu o cały zasób wiedzy i doświadczenia, możliwości poznawcze, a także informacje z kontekstu prowadzonego dyskursu dostępne komunikujacym się podmiotom. To dzięki ich zaangażowaniu w konceptualizację poznający umysł jest w stanie integrować napływające informacje, ustalając odwzorowania między elementami z poszczególnych przestrzeni tworzonego amalgamatu. W zamyśle autorki artykuł stanowi uzupełnienie semantyczno-gramatycznego opisu fenomenu wieloznaczności dokonanego przy pomocy metod językoznawstwa kognitywnego o badanie nadawczo-odbiorczych aspektów komunikowania wieloznacznego, możliwe jedynie poprzez wykorzystanie metod właściwych naukom społecznym (w tym przypadku stosowanego powszechnie na gruncie psychologii planu eksperymentalnego).

${ }^{7}$ Por. J.R. Taylor, Kategoryzacja $w$ języku. Prototypy $w$ teorii językoznawczej, przekład A. Skucińska, Universitas, Kraków 2001.

${ }^{8}$ Por. E. Tabakowska, Językoznawstwo kognitywne a poetyka przekładu, przeł. A. Pokojska, Universitas, Kraków 2001; E. Tabakowska, Kognitywne podstawy języka i językoznawstwa, Universitas, Kraków 2001.

${ }^{9}$ Wśród klasycznych dziś już prac z zakresu komunikacji politycznej i marketingu politycznego traktujących na temat wieloznaczności w komunikacji wymienić należy przede wszystkim: P. Bull, Slipperiness, evasion and ambiquity. Equivocation and facework in noncommittal political discourse, „Journal of Personality and Social Psychology” 2008, nr 27 (4), s. 333-344; tenże, Slippery politicians?, „The Psychologist” 2003, nr 16 (11), s. 592-595; P. Bull, K. Mayer, How to answer in polical interviews, „Political Psychology” 1993, nr 14(4), s. 651-666; J.E. Cambell, Ambiguity in the issue positions of presidential candidates. A casual analysis, "American Journal of Political Science" 1983, $\mathrm{nr} 27$ (2), s. 284-293; D.Walton, New dialectical rules for ambiquity, „Informal Logic” 2000, $\mathrm{nr} 20$ (3), s. 261-274; M.L. Williams, B. Goss, Equivocation: How does it affect receiver agrement and recall, "Central States Speech Journal", nr 31(1), s. 30-41; C. Camden, M.T. Moltey, A. Wilson, White lies in interpersonal communication. A taxonomy and preliminary investigation of social motivations, "Western Journal of Speech Communication" 1984, nr 48(4), s. 309-325. Żadna z tych prac, choć wszystkie poświęcone są efektowi perswazyjnemu w polityce, nie traktuje wieloznaczności w kategoriach fenomenu komunikacyjnego (a więc pierwotnie - językowego).

${ }^{10}$ Niniejsza praca stanowi kolejną w cyklu poświęconych wieloznaczności poznawczej w komunikacji, w ramach którychów fenomen badany i analizowany jest przez autorkę szerzej ani- 


\section{Wieloznaczność poznawcza w komunikacji ${ }^{11}$ a efekt perswazyjny komunikatu}

Kognitywne analizy kategorialne tekstowych emanacji wieloznaczności na materiale komunikowania polityków ujawniły hierarchiczną strukturę wieloznaczności poznawczej, uobecnianą w komunikacji na różnych poziomach konceptualizacji:

a) podstawowym, gdy jest ona konsekwencją polisemicznej natury pojęć, tj. pojęć z więcej niż jednym centrum i radialną strukturą (np. SPRAWIEDLIWOŚĆ, tj. wartość/postawavs. WYMIAR SPRAWIEDLIWOŚCI, tj. instytucja państwa), których zakres, mimo iż jest znany, z uwagi na policentryczność kategorii pozostaje niedookreślony (inaczej niż ma się to w przypadku kategorii stricte monosemicznych typu PTAK); rola kreacyjności odbiorcy w przetwarzaniu informacji komunikowanych na tym poziomie jest zawężona zakresem kategorii ${ }^{12}$;

b) na tzw. poziomie drugim, gdy wieloznaczność powstaje w wyniku stopienia dwóch lub więcej domen wyjściowych (kategorii monosemicznych lub monosemicznych i polisemicznych) w polisemiczny z natury amalgamat (np. DOBROBYT POLSKI), stanowiąc konsekwencję procesów kompresji i dekompresji zawartości przestrzeni wyjściowych (polisemicznej kategorii DOBROBYT oraz monosemicznej kategorii POLSKA) w przestrzeń generyczną; na tym poziomie

żeli na poziomie systemu językowego, z wykorzystaniem właściwego kognitywistyce, swoistej koalicji nauk: biologii, psychologii, filozofii czy nauki o języku, paradygmatu myślenia. Analiza wieloznacznych komunikatów z perspektyw kognitywnej semantyki i gramatyki umożliwiła opis wieloznaczności jako zjawiska wynikającego wprost z właściwości ludzkiego myślenia, z natury nieścisłego i „mętnego”, wpisanego w każdą komunikację i dla niej naturalnego (por. K. Dobrosz-Michiewicz, Struktura wieloznaczności poznawczej (na podstawie komunikowania w polityce), „Acta Universitatis Lodziensis. Folia Litteraria Polonica” 2016, nr 2 (32), s. 187-205). Wykorzystanie właściwych naukom społecznym metod badawczych pozwoliło scharakteryzować fenomen wieloznaczności w komunikacji z perspektywy relacji nadawczo-odbiorczej: wpływu jej zastosowania w komunikacji na ocenę kompetencji i wiarygodności nadawcy wieloznacznego komunikatu (por. K. Dobrosz-Michiewicz, Funkcjonalne aspekty komunikowania wieloznacznego - ocena nadawcy komunikatu, [w:] Communicationdesing: badanie i projektowanie komunikacji 5, red. M. Wszołek [w druku]) oraz - co jest przedmiotem niniejszych badań - wpływu wieloznaczności w komunikacji na osiągany przez komunikat efekt perswazyjny.

${ }^{11} \mathrm{~W}$ badaniach posłużono się konstruktem wieloznaczności poznawczej, wypracowanym uprzednio na gruncie kognitywnych analiz językoznawczych, prowadzonych na materiale z zakresu komunikowania polityków. Na potrzeby niniejszej pracy przytoczone zostały jedynie główne wnioski z kategorialnych analiz wieloznaczności poznawczej na materiale wystąpień programowych polskich polityków, szeroko omówionych w artykule Struktura wieloznaczności poznawczej...

${ }^{12}$ H. Kardela, (Nie)podobieństwo w morfologii: amalgamaty kognitywne, [w:] Kognitywistyka. Podobieństwo, red. H. Kardela, Z. Muszyński, M. Rajewski, Wydawnictwo UMCS, Lublin 2006, s. 201. 
konceptualizacji wieloznaczności znacząco rozszerza się rola kreacyjności odbiorcy w przetwarzaniu informacji13; szczególnym przypadkiem wieloznaczności poziomu drugiego jest tzw. wieloznaczność wyższego rzędu, z którą mamy do czynienia, gdy amalgamaty konceptualne powstają ze stopienia wyłącznie polisemicznych kategorii (np. DOBRA ZMIANA), których zakres nie został w żaden sposób dookreślony w komunikacji; rola kreacyjności odbiorcy w przetwarzaniu informacji jest zawężona jedynie granicami jego własnej percepcji.

W jaki sposób tak rozumiana wieloznacznośćpoznawcza, manifestowana w komunikacji na różnych poziomach konceptualizacji, przekłada się na osiągany przez komunikat efekt perswazyjny (rozumiany jako zgoda odbiorców komunikatu wobec komunikowanych treści)? Innymi słowy: czy dla stosowanej w polityce strategii wieloznaczności istnieją komunikacyjne ograniczenia? Jeśli tak, to jakie?

W poszukiwaniu odpowiedzi na powyższe pytania w okresie maj-czerwiec 2016 roku w Uniwersytecie Łódzkim przeprowadzono serię quasi-eksperymentalnych badań z udziałem losowo wybranych studentów ( $N=300$ ) w wieku 20-24 lata. Uzyskane wyniki pozwoliły wyprowadzić następujące wnioski w zakresie operowania wieloznacznością poznawczą w komunikacji:

1) im wyższy poziom wieloznaczności komunikatu, tym wyższa zgoda odbiorców z komunikowanymi treściami; wieloznaczność w komunikacji stanowi swoisty inhibitor sprzeciwu odbiorców wobec komunikowanych treści (wariant 1 i 2 badania);

2) powyższa zasada nie ma zastosowania w przypadku komunikowania w sytuacji wcześniej spolaryzowanych postaw odbiorców - wieloznaczność występuje jako strategia utrzymania status quo, za jej pomocą nie przekonamy dotąd nieprzekonanych, ale również nie zniechęcimy nam przychylnych (wariant 3 i 4 badania);

3) ograniczeniem dla zastosowania wieloznaczności jako strategii komunikacyjnej obliczonej na efekt perswazyjny jest współwystępowanie komunikatów operujących na różnych poziomach wieloznaczności; obecność komunikatu operującego wieloznacznością poziomu podstawowego osłabia wpływ wieloznaczności wyższego rzędu na możliwość osiągnięcia efektu (wariant 5);

4) postawy ukształtowane przy pomocy komunikatów operujących na wyższym poziomie konceptualizacji wieloznaczności są mniej odporne na zmianę (eksperyment 3).

13 Tamże, s. 203. 


\section{Procedura badawcza oraz uzyskane wyniki}

W serii quasi-eksperymentalnych ${ }^{14}$ badań $(\mathrm{N}=300)$ w podgrupach $(\mathrm{N}=30)$ uczestnikom prezentowano komunikaty operujące na różnych poziomach wieloznaczności ${ }^{15}$ : komunikat A, operujący wieloznacznością wyższego rzędu, oraz jego parafrazę - komunikat B, operujący na poziomie podstawowym wieloznaczności.

W wariancie pierwszym badania uczestników $(\mathrm{N}=60)$ proszono o określenie na pięciostopniowej skali Likerta, „na ile zgadzają się z treścią prezentowanego komunikatu/stopnia poparcia” (przy czym 5 oznaczało stanowczo jestem „,za”, zaś 1 - trudno powiedzieć). Połowie badanych zaprezentowano komunikat A, połowie B (grupy niezależne). Uzyskane wyniki wskazywały na istotną (w sensie statystycznym) różnicę w zakresie średniej oceny zgodności z komunikatem ewokującym wieloznaczność wyższego rzędu $(S=4,4)$ w stosunku do zgodności z komunikatem ewokującym wieloznaczność poziomu podstawowego $(S=2,6)$. Amalgamatyczność komunikatów sprzyja uzyskaniu przez ich nadawcę efektu perswazyjnego.

${ }^{14}$ Szeroko o metodologii badań eksperymentalnych traktuje opracowanie D.T. Cambell, J.C. Stanley, Experimental and quasi-experimental design for research on teaching, [w:] Handbook of research and teaching, (red.) N.L. Gage, Chicago 1967, s. 171-246; wśród publikacji polskich zaś: J. Brzeziński, Metodologia badań psychologicznych, Wydawnictwo Naukowe PWN, Warszawa 2003 oraz: tenże, Badania eksperymentalne w psychologii i pedagogice, Wydawnictwo Naukowe Scholar, Warszawa 2008.

${ }^{15}$ Komunikat A, silnie amalgamatyczny, operujący wieloznacznością wyższego rzędu: Musimy podjąć wyzwania przyszłości. A te sa jasne. Musimy wyrwać się z pułapki średniego rozwoju. To znaczy przyspieszyć tempo wzrostu. Podjać rozwiąania wszystkich problemów, przed którymi stoimy w sferze gospodarczej, spraw społecznych $i$ stanu państwa. Jeśli chodzi o jego kondycję wewnętrzna i międzynarodowa. Stany gospodarki, spraw społecznych i państwa nie sa na poziomie realnych procesów społecznych rozdzielnych. Przeciwnie. Wiąż się ze soba i to zarówno wtedy, kiedy występuja zjawiska negatywne, jak i pozytywne. W tym ostatnim wypadku można uzyskać synergię. Wzajemne wzmacnianie się pozytywnych procesów. Komunikat B, stanowił parafrazę komunikatu A, operując na poziomie podstawowym wieloznaczności, tj. dla części amalgamów konceptualnych dookreślono niedookreślony jak dotąd zakres przynajmniej jednej z przestrzeni wyjściowych, najczęściej poprzez zdefiniowanie zakresu monosemicznej kategorii: Musimy podjać wyzwania przyszłości, tj. na najbliższe 4 lata. A te sa jasne. Musimy wyrwać się z pułapki średniego rozwoju. To znaczy przyspieszyć tempo wzrostu, przynajmniej o 3-4\% PKB. Podjać rozwiązania wszystkich problemów, przed którymi stoimy w sferze gospodarczej (wsparcie przedsiębiorców), spraw społecznych (pomoc rodzinie i najuboższym, program mieszkaniowy) i stanu państwa (usprawnienie administracji). Jeśli chodzi o jego kondycję wewnętrzna i międzynarodowa. Stany gospodarki, spraw społecznych i państwa nie sa na poziomie realnych procesów społecznych rozdzielnych. Przeciwnie. Wiąża się ze soba i to zarówno wtedy, kiedy występuja zjawiska negatywne, gdy kryzys gospodarczy oznacza ubożenie obywateli, jak i pozytywne, gdy poprawa sytuacji gospodarczej oznacza wzrost naszej zasobności. W tym ostatnim wypadku można uzyskać synergię. Wzajemne wzmacnianie się pozytywnych procesów. 
Podobnie istotną różnicę zaobserwowano, gdy badanych $(\mathrm{N}=60)$ poproszono o określenie na pięciostopniowej skali Likerta, na ile „są przeciwni” prezentowanym w komunikacie treściom" (wariant 2), przy czym 5 oznaczało stanowczo jestem przeciw, zaś 1 - trudno powiedzieć. Uzyskane w tym przypadku wyniki (odpowiednio dla komunikatu A: $\mathrm{S}=3,6$; dla komunikatu B: $\mathrm{S}=4,4$ ) wskazywały jednak na odwrotny kierunek zależności. O ile wyższy poziom konceptualizacji wieloznaczności komunikatu sprzyjał postawie „za”, o tyle poziom podstawowy sprzyjał postawie ,przeciw”. W tym sensie więc strategia komunikacyjna oparta na operowaniu wieloznacznością mogłaby okazać się skutecznym narzędziem kształtowania spolaryzowanych postaw, zarówno „za”, jak i „przeciw”. Czy taką samą funkcję wieloznaczność mogłaby pełnić w sytuacji, w której już ukształtowane postawy wymagałyby zmiany za pomocą komunikacji?

W poszukiwaniu odpowiedzi na powyższe pytanie zrealizowano kolejne badania quasi-eksperymentalne $(\mathrm{N}=120)$. Tym razem badanych uprzednio poproszono o wypełnienie krótkiej ankiety demograficznej, w której w ramach tzw. zadania buforowego ${ }^{16}$ poproszono ich o wskazanie swoich preferencji politycznych według stanu na dzień badania. Następnie czterem niezależnym grupom zaprezentowano odpowiednio komunikaty A oraz B wraz z informacją, iż są fragmentem przemówienia „partii przez nich popieranej” (wariant 3; dwie grupy, każda $\mathrm{N}=30$ ) lub „partii z tzw. przeciwnego bieguna sceny politycznej” (wariant 4; dwie grupy, każda $\mathrm{N}=30$ ). Badanych poproszono o ocenę odpowiednio: „na ile są za” vs. „na ile są przeciw” prezentowanym treściom na pięciostopniowej skali Likerta, gdzie 5 oznaczało stanowczo jestem za/przeciw, zaś 1 - trudno powiedzieć. Uzyskane wyniki nie ujawniły wskazanego w wariancie 1 i 2 badania prymatu wieloznaczności wyższego rzędu nad wieloznacznością poziomu podstawowego w zakresie wywoływania efektu perswazyjnego. Zarówno w przypadku wariantu „za”, jak i „przeciw” poziom wieloznaczności nie różnicował oceny odbiorcy (odpowiednio $\mathrm{S}=4,4$ dla tekstu A i $\mathrm{S}=4,2$ dla tekstu B w wariancie ,za” oraz $\mathrm{S}=1,2$ dla A i $\mathrm{S}=1$ dla B w wariancie ,przeciw”). Uprzednio spolaryzowane postawy wydają się stanowić istotne ograniczenie skuteczności (rozumianej jako osiągniecie efektu perswazyjnego) wieloznacznego komunikatu. W tym sensie komunikacyjna strategia oparta na operowaniu wieloznacznością stanowiłaby raczej strategię „,utrzymania status quo"aniżeli strategię „,komunikowania zmiany”. Powyższy wniosek rodzi również pytanie o trwałość postaw ukształtowanych pod wpływem wieloznacznych komunikatów.

Aby na nie odpowiedzieć, w ramach ostatniego wariantu badania poproszono uczestników ( $\mathrm{N}=60)$ o wypełnienie ankiety demograficznej (tej samej, którą wypełniali badani w wariancie 3 i 4), a następnie wybór komunikatu uznane-

16 Tzn. maskującego właściwy cel badania (standardowa praktyka w badaniach eksperymentalnych). 
go za bardziej wiarygodny (spośród komunikatów A: 28\% i B: 72\%). Następnie informowano badanych, iż niewybrany przez nich komunikat jest fragmentem wystąpienia przedstawiciela partii z tzw. przeciwnego bieguna politycznego oraz proszono o ponowną ocenę wiarygodności komunikatu. Zaledwie $17 \%$ (z 72) oceniających jako bardziej wiarygodny komunikat ewokujący wieloznaczność poziomu podstawowego zdecydowało się zmienić zdanie - inaczej niż w przypadku komunikatu ewokującego wieloznaczność wyższego rzędu (aż 73\% z 28). O ile więc wyższy poziom konceptualizacji wieloznaczności przyczyniać się może do wzmocnienia efektu perswazyjnego, o tyle efekt ów może okazać się mniej trwały (a ukształtowana przy jego pomocy postawa - tymczasowa). Co istotne, wyniki uzyskane w ostatnim wariancie badania wydają się nie potwierdzać zależności pomiędzy wyższym poziomem konceptualizowania wieloznaczności a uzyskanym efektem perswazyjnym. Może to wskazywać raczej na podyktowane współwystępowaniem komunikatów o różnym poziomie konceptualizacji ograniczenie reguły wypracowanej w ramach badania $\mathrm{w}$ wariancie 1 i 2 , aniżeli na procesy podecyzyjne (zmiana zaszła bowiem w odniesieniu do obu komunikatów), bez wątpienia jednak wymaga dalszych badań w wymienionym zakresie.

\section{Bibliografia}

Bull P., Slipperypoliticians?, „The Psychologist” 2003, nr 16 (11), s. 592-595.

Camden C., Moltey M.T., Wilson A., White lies in interpersonalcommunication. A taxonomy and preliminaryinvestigation of socialmotivations, "Western Journal of Speech Communication" 1984, nr 48(4), s. 309-325.

Cwalina W., Wieloznaczność poznawcza w komunikacji, [w]: Psychologia poznawcza w praktyce: ekonomia, biznes, polityka, red. A. Falkowski, T. Zaleśkiewicz, Wydawnictwo Naukowe PWN, Warszawa 2012.

Dobrosz-Michiewicz K., Funkcjonalne aspekty komunikowania wieloznacznego - ocena nadawcy komunikatu, [w:] Communicationdesing: badanie i projektowanie komunikacji 5, red. M. Wszołek [w druku].

Dobrosz-Michiewicz K., Struktura wieloznaczności poznawczej(na podstawie komunikowania w polityce), „Acta Universitas Lodziensis. Folia Litteraria Polonica” 2016, nr 2 (32), s. 187-205.

Falkowski A., Podobieństwo poznawcze w kategoryzacji percepcyjnej. Badania empiryczne w egzemplarzowym modelu kategoryzacji, „Przegląd Psychologiczny” 1990, nr 33, s. 293-312.

Ferreira F., Bailey K.G.D., Ferraro V., Good-enoughrepresentation in languagecomprehension, "CurrentDirections in Psychological Science" 2002, nr 11(1), s. 11-15.

Kardela H., (Nie)podobieństwo w morfologii: amalgamaty kognitywne, [w:] Kognitywistyka. Podobieństwo, red. H. Kardela, Z. Muszyński, M. Rajewski, Wydawnictwo UMCS, Lublin 2006, s. 195-211.

Tabakowska E., Gramatyka i obrazowanie. Wprowadzenie do językoznawstwa kognitywnego, Polska Akademia Nauk, Warszawa 1995.

Tabakowska E., Językoznawstwo kognitywne a poetyka przekładu, przeł. A. Pokojska, Univeristas, Kraków 2001. 
Tabakowska E., Kognitywne podstawy języka i językoznawstwa, Universitas, Kraków 2001. Taylor J.R., Kategoryzacja w języku. Prototypy w teorii językoznawczej, Univeristas, Kraków 2001.

\author{
Karolina Dobrosz-Michiewicz
}

\title{
Cognitive ambiguity phenomena as a communication strategy
}

(Summary)

The paper presents the results of empirical experimental research on the influence of ambiguity of communication on the message persuasive effect. The results obtained have led, in principle, to the following conclusions regarding cognitive ambiguity phenomena in communication:

1) The higher the message ambiguity means the higher the consensus of the recipients with the communicated content; ambiguity in communication constitutes a specific inhibitor of audience opposition to communicated content.

2) The rule above does not apply to communication in the case of previously polarized attitudes of the audience (ambiguity as a strategy of maintaining the status quo- with its help we will not be convinced until now, but we also do not discourage us).

3) The limitation for the use of ambiguity as a communication strategy calculated on the persuasive effect is the coexistence of messages operating at different levels of ambiguity; The presence of a message that operates the ambiguity of the base level in the message weakens the effect of higher order ambiguity on the agreement reached by the persuasive message.

4) Attitudes shaped by messages operating at a higher level of conceptualization of ambiguity are less resistant to change.

Keywords: ambiguity, cognitive phenomena, mental categorization, ambiguity and pesrsuation, cognitive grammar and cognitive semantics, multilevelled ambiguity. 